\title{
Avaliação da qualidade microbiológica de cápsulas e chás de plantas utilizadas na assistência ao tratamento da obesidade
}

\author{
VERDI, Susana '; YOUNES, Salua'; BERTOL, Charise D. *,1 \\ ${ }^{1}$ Controle de Qualidade, Curso de Farmácia, Universidade de Passo Fundo, Passo Fundo/RS, Brasil, CEP: \\ 99001-970; ${ }^{2}$ Laboratório de Análises Clínicas, Curso de Farmácia, Universidade de Passo Fundo, Passo \\ Fundo/RS, Brasil, CEP: 99001-970; * Autor correspondente: Charise D. Bertol. Endereço: Universidade de \\ Passo Fundo, Curso de Farmácia, Campus I, Caixa Postal 611, Km 171, BR 285, CEP 99001-970, Bairro São \\ José, Passo Fundo/ RS. Fone/Fax: (54) 3316-8499. E-mail: charise@upf.br
}

\begin{abstract}
RESUMO: O uso de plantas diuréticas e laxativas é uma alternativa medicamentosa para muitas pessoas que objetivam o emagrecimento com menores efeitos adversos. A avaliação microbiológica é um requisito essencial para a garantia de qualidade dos produtos. A finalidade deste trabalho foi avaliar a qualidade microbiológica de cápsulas e chás de alcachofra (Cynara scolymus L.), centella asiática (Hydrocotile asiatica L.), fucus (Fucus vesiculosus L.), e sene (Cassia acutifolia Delile), através da contagem de micro-organismos viáveis totais e pesquisa de patógenos. Na contagem de micro-organismos viáveis, os chás analisados foram aprovados, pois apesar de apresentarem uma carga microbiana elevada, esta se encontrava dentro das especificações, entretanto, $16,66 \%$ e $66,66 \%$ das cápsulas analisadas foram reprovadas por apresentaram quantidades superiores de bactérias e fungos, respectivamente. Na pesquisa de patógenos, $76 \%$ das amostras ( $88 \%$ dos chás e $58 \%$ das cápsulas) apresentaram um ou mais de um tipo de micro-organismo. Salmonella sp. esteve presente em $33 \%$ das amostras evidenciando a qualidade microbiológica insatisfatória dos produtos encontrados no mercado. Estes resultados demonstram a necessidade da realização do controle de qualidade tanto das matérias-primas vegetais, quanto dos produtos acabados, através do controle e fiscalização rigorosa, com adoção de medidas regulamentadoras e educativas.
\end{abstract}

Palavras-chave: Alcachofra, Centella, Controle Microbiológico, Fucus, Sene.

ABSTRACT: Microbiological quality evaluation of herbal capsules and teas to assist the treatment of obesity. The use of laxative and diuretic herbal drugs is an alternative therapy for many people looking for loosing weight with fewer side effects. The microbiological evaluation is an essential requirement for the quality assurance of products. This study aimed to evaluate the microbial quality of artichoke (Cynara scolymus L.), centella (Hydrocotile asiatica L.), fucus (Fucus vesiculosus L.), and Senna (Cassia acutifolia Delile) capsules and teas, by counting the total viable aerobic microorganisms and through tests for specified microorganisms. On the total viable aerobic microorganisms count, the teas analyzed were approved, because although they had a high microbial load, this was in accordance with the specifications, however $16.66 \%$ and $66.66 \%$ of the capsules analyzed were rejected because they presented higher amounts of bacteria and fungi, respectively. In relation to the tests for specified microorganisms, $76 \%$ of the samples ( $88 \%$ of the teas and $58 \%$ of the capsules) presented one or more than one type of microorganisms. Salmonella sp. was present in $33 \%$ of the samples, showing the unsatisfactory microbial quality of the products in the market. These results demonstrate the necessity of performing quality control both on herbal raw material and finished products, through a rigorous control and inspection, adopting regulatory and educational measures.

Key words: Artichoke, Centella, Microbial Control, Fucus, Senna.

Recebido para publicação em 27/04/2012

Aceito para publicação em 30/01/2013

Rev. Bras. Pl. Med., Campinas, v.15, n.4, p.494-502, 2013. 


\section{INTRODUÇÃO}

A obesidade é uma doença caracterizada pelo acúmulo excessivo de gordura corporal e se constitui um problema de Saúde Pública, atingindo todas as faixas etárias e níveis sociais, estando relacionada a má alimentação, falta de atividade física, urbanização, desequilíbrio hormonal e emocional, entre outros (Abeso, 2011). Os medicamentos sintéticos para o tratamento da obesidade atuam no sistema nervoso central e podem ocasionar diversos efeitos colaterais (insônia, cefaléia, irritabilidade, depressão, etc.) e, ainda necessitam de prescrição médica especial e acompanhamento terapêutico inviabilizando o tratamento de pessoas carentes. Atualmente, desde o dia 4 de outubro de 2011, muito desses medicamentos sintéticos - derivados anfetamínicos - foram proibidos pela Agência Nacional de Vigilância Sanitária (ANVISA) devido a seus efeitos colaterais e ao uso abusivo (Brasil, 2011).

O uso de medicamentos e chás de origem vegetal é uma alternativa medicamentosa para muitas pessoas que objetivam o emagrecimento com menores efeitos adversos e economicamente viáveis (Zaroni et al., 2004). Estima-se que as vendas globais de produtos à base de plantas totalizaram cerca de 60 milhões de dólares em 2000. Como consequência a segurança e a qualidade dos medicamentos tornam-se preocupações cada vez mais importantes para as autoridades de saúde pública (WHO, 2003).

Muitas plantas são utilizadas com finalidade de emagrecimento. Dentre essas plantas encontrase a alcachofra (Cynara scolymus L.) com ação hepatoestimulante, colerética, hipocolesterolêmica, diurética e colagoga; a centella asiática (Hydrocotile asiatica L.) que tem ação diurética; o fucus (Fucus vesiculosus L.) que apresenta ação diurética, estimulante da tireóide e promove um aumento do trânsito intestinal; e o sene (Cassia acutifolia Delile) que é laxativo (Teske \& Trentini, 2003; D'Ippolito et al., 2005).

No Brasil, o principal órgão responsável pela regulamentação de plantas medicinais e seus derivados é a ANVISA que visa garantir a segurança da saúde da população (Carvalho et al., 2008; Brasil, 2010a). Apesar dos esforços, a prática da fitoterapia segura encontra diversas dificuldades, que vão, desde a identificação correta do material botânico à inexistência de estudos de segurança, eficácia e qualidade (Carvalho et al., 2008; Rocha et al., 2009). Além disso, muitos produtores desconhecem os cuidados que se deve ter nas diversas etapas para a obtenção de matériasprimas e produtos com adequada qualidade (Zaroni et al., 2004). Os problemas mais frequentes estão relacionados à origem da matéria-prima e às condições inadequadas de armazenamento durante a comercialização e a manipulação (exposição à poeira, calor, umidade, insetos e micro-organismos).

O controle de qualidade microbiológico é realizado para assegurar que a carga microbiana presente, não comprometa a qualidade final ou segurança do paciente (Pinto et al., 2003; Rocha et al., 2009). A contaminação por bactérias e fungos pode levar a degradação ou alteração das substâncias ativas e ocasionar a produção de substâncias tóxicas (Luiza et al., 1999), além de representar risco potencial de aquisição de quadro clínico infeccioso.

Muitos estudos demonstram elevados índices de contaminação microbiana em materiais vegetais, além de presença de patógenos (Limyati \& Juniar, 1998; Araújo \& Ohara, 2000; Martins et al., 2001; Zaroni et al., 2004; Bianco et al., 2008; Müller \& Basedow, 2007).

Neste contexto, foram selecionadas para avaliação da qualidade microbiológica amostras de plantas comercializadas em sacos plásticos (chás) e em cápsulas de alcachofra, centella asiática, fucus e sene, disponíveis comercialmente devido ao elevado consumo no tratamento auxiliar da obesidade. As amostras foram submetidas à contagem de microorganismos viáveis totais (bactérias e fungos) e pesquisa de patógenos.

\section{MATERIAL E MÉTODO}

\section{Material vegetal}

As amostras utilizadas foram cápsulas e chás de alcachofra (Cynara scolymus L.), centella asiática (Hydrocotile asiatica L.), fucus (Fucus vesiculosus L.) e sene (Cassia acutifolia Delile) adquiridas comercialmente, totalizando 21 amostras (9 amostras de chás e 12 de cápsulas). Os fornecedores (fabricantes/ farmácias de manipulação) foram designados genericamente pelas letras A (Passo Fundo/ RS), B (Passo Fundo/ RS), C (Valinhos/ SP), D (Chapecó/ SC) e E (Colombo/ PR). Nas cápsulas as plantas encontravam-se na forma pulverizada e nos chás na forma de folhas, caules, ou partes da planta seca embalados em sacos plásticos.

\section{totais}

Contagem de micro-organismos viáveis

Foram pesadas $10 \mathrm{~g}$ de cada amostra diluídas em peptona bacteriológica contendo $1 \%$ de polissorbato 80 . As análises foram realizadas pela técnica de semeadura em profundidade (Pour Plate) em duplicata nas seguintes diluições 1:20, 1:200 e 1:2000, onde foi adicionado $1 \mathrm{~mL}$ de cada diluição

Rev. Bras. Pl. Med., Campinas, v.15, n.4, p.494-502, 2013. 
em placas de petry estéreis e posteriormente o ágar soja-caseína ou ágar batata liquefeito para contagem, respectivamente, de bactérias e fungos. As placas foram incubadas a $35^{\circ} \mathrm{C}$ por 5 dias para pesquisa de bactérias e a $25^{\circ} \mathrm{C}$ por 7 dias para pesquisa de fungos. Os meios de cultura utilizados foram preparados conforme especificação do fabricante e autoclavados a $121^{\circ} \mathrm{C}$ por 20 minutos. As análises foram realizadas em capela de fluxo laminar (modelo VLPS18CL2A, Veco, Campinas/ $\mathrm{SP}$ ), acompanhadas de controle ambiental e controles dos meios de cultura (Brasil, 2010b). Após o período de incubação as colônias foram contadas, multiplicadas pelo fator de diluição, e o número de unidades formadoras de colônias (UFC) por grama de material vegetal foi calculado.

\section{Pesquisa de Patógenos}

Foram pesadas $1 \mathrm{~g}$ de cada amostra, adicionou-se $30 \mathrm{~mL}$ de caldo de enriquecimento estéril (contendo caldo de caseína de soja, peptona de carne, extrato de levedura, $1 \%$ de polissorbato 80) e incubou-se a $35^{\circ} \mathrm{C}$ por $48 \mathrm{~h}$. Estrias do caldo contendo a amostra enriquecida foram semeadas, com auxílio de alça de platina, na superfície dos meios de cultura seletivos (Brasil, 2010b).

$\mathrm{Na}$ presença de crescimento de colônias suspeitas foram realizados testes confirmatórios. Foram utilizados o ágar verde brilhante e o ágar Mac Conkey para pesquisa de Salmonella sp e Escherichia coli respectivamente e, para confirmação foram realizados repiques das colônias em ágar TSI (triple sugar iron), lisina, SIM (sulfeto, indol, motilidade), citrato e uréia. Na pesquisa de Staphylococcus aureus, as colônias crescidas no ágar Vogel-Jhonson, foram submetidas ao teste da catalase, onde se pingou uma gota de peróxido de hidrogênio sobre as colônias. O gênero estafilococos é confirmado se há formação de bolhas, considerando catalase-positivo. $O$ teste de coagulase foi realizado para confirmação da espécie (aureus). Neste teste da coagulase, a colônia foi inoculada em um tubo de ensaio contendo 500 iL de plasma (utilizando citrato como anticoagulante) e incubou-se a $37^{\circ} \mathrm{C}$ por $24 \mathrm{~h}$. A formação de coágulos (gel) após a incubação é interpretada como uma prova positiva. Para confirmação de Pseudomonas aeruginosa, as colônias crescidas no ágar cetrimida foram submetidas ao teste das tiras de oxidase e foram realizados repiques destas colônias no ágar Mueller Hinton.

\section{RESULTADO}

Os resultados obtidos na contagem de micro-organismos viáveis totais encontrados nos produtos (chás e cápsulas) e seus fornecedores
TABELA 1. Contagem de micro-organismos viáveis totais de chás e cápsulas.

\begin{tabular}{|c|c|c|c|}
\hline $\begin{array}{l}\text { Planta } \\
\text { medicinal }\end{array}$ & $\begin{array}{l}\text { Produtol } \\
\text { Fornecedor }\end{array}$ & $\begin{array}{l}\text { Bactérias } \\
\text { (UFC/g) }\end{array}$ & $\begin{array}{l}\text { Fungos } \\
\text { (UFC/g) }\end{array}$ \\
\hline \multirow[t]{6}{*}{ Alcachofra } & Chá/ A & $1,56 \cdot 10^{4}$ & $4,26 \cdot 10^{3}$ \\
\hline & Chá/ C & $1,43 \cdot 10^{2}$ & $7,33 \cdot 10^{1}$ \\
\hline & Chá/ D & $1,33 \cdot 10^{5}$ & $1,40 \cdot 10^{3}$ \\
\hline & Cápsula/ A & $5,63 \cdot 10^{3}$ & $1,02 \cdot 10^{3}$ \\
\hline & Cápsula/ B & $2,66 \cdot 10^{1}$ & $1,00 \cdot 10^{4}$ \\
\hline & Cápsula/ E & $<10$ & $1,00 \cdot 10^{3}$ \\
\hline \multirow[t]{5}{*}{ Centella } & Chá/ A & $1,60 \cdot 10^{4}$ & $4,06 \cdot 10^{2}$ \\
\hline & Chá/ C & $<10$ & $<10$ \\
\hline & Cápsula/ A & $1,40 \cdot 10^{2}$ & $1,76 \cdot 10^{2}$ \\
\hline & Cápsula/ B & $1,20 \cdot 10^{3}$ & $2,63 \cdot 10^{2}$ \\
\hline & Cápsula/ E & $6,70 \cdot 10^{2}$ & $1,00 \cdot 10^{3}$ \\
\hline \multirow[t]{4}{*}{ Fucus } & Chá/ A & $1,66 \cdot 10^{3}$ & $1,38 \cdot 10^{3}$ \\
\hline & Cápsula/ A & $3,46 \cdot 10^{2}$ & $<10$ \\
\hline & Cápsula/ B & $1,44 \cdot 10^{5}$ & $1,00 \cdot 10^{1}$ \\
\hline & Cápsula/ E & $<10$ & $<10$ \\
\hline \multirow[t]{6}{*}{ Sene } & Chá/ A & $4,30 \cdot 10^{4}$ & $6,74 \cdot 10^{3}$ \\
\hline & Chá/ C & $7,66 \cdot 10^{3}$ & $3,70 \cdot 10^{3}$ \\
\hline & Chá/ D & $1,64 \cdot 10^{5}$ & $1,40 \cdot 10^{3}$ \\
\hline & Cápsula/ A & $6,10 \cdot 10^{3}$ & $4.06 \cdot 10^{2}$ \\
\hline & Cápsula/ B & $2,13 \cdot 10^{4}$ & $1,11.10^{4}$ \\
\hline & Cápsula/ E & $<10$ & $1,00 \cdot 10^{3}$ \\
\hline
\end{tabular}

estão representados na tabela 1 . Na figura 1 está representado o percentual de reprovação das cápsulas em relação à contagem de bactérias e fungos viáveis. Este percentual de reprovação foi calculado considerando o número total de amostras de cápsulas analisadas (12 amostras) e utilizando a especificação da Farmacopeia Brasileira $5^{\mathrm{a}} \mathrm{Ed}$. (Brasil, 2010b) como referência.

$\mathrm{Na}$ pesquisa de patógenos nos meios presuntivos seletivos (ágar verde brilhante, ágar Mac Conkey, ágar Vogel Jhonson, ágar cetrimida), para a alcachofra o chá do fornecedor A apresentou crescimento em todos os meios, enquanto o chá do fornecedor $C$ apresentou crescimento apenas no ágar Vogel Jhonson e, o chá do fornecedor $D$ apenas no ágar verde brilhante. Já as cápsulas do fornecedor A apresentaram crescimento no ágar verde brilhante (dois tipos de colônias com distintos aspectos macroscópicos) e no ágar cetrimida, as cápsulas do fornecedor B apresentaram crescimento no ágar Vogel Jhonson e as cápsulas do fornecedor E não apresentaram crescimento nos meios. Para a centella o chá do fornecedor A apresentou 


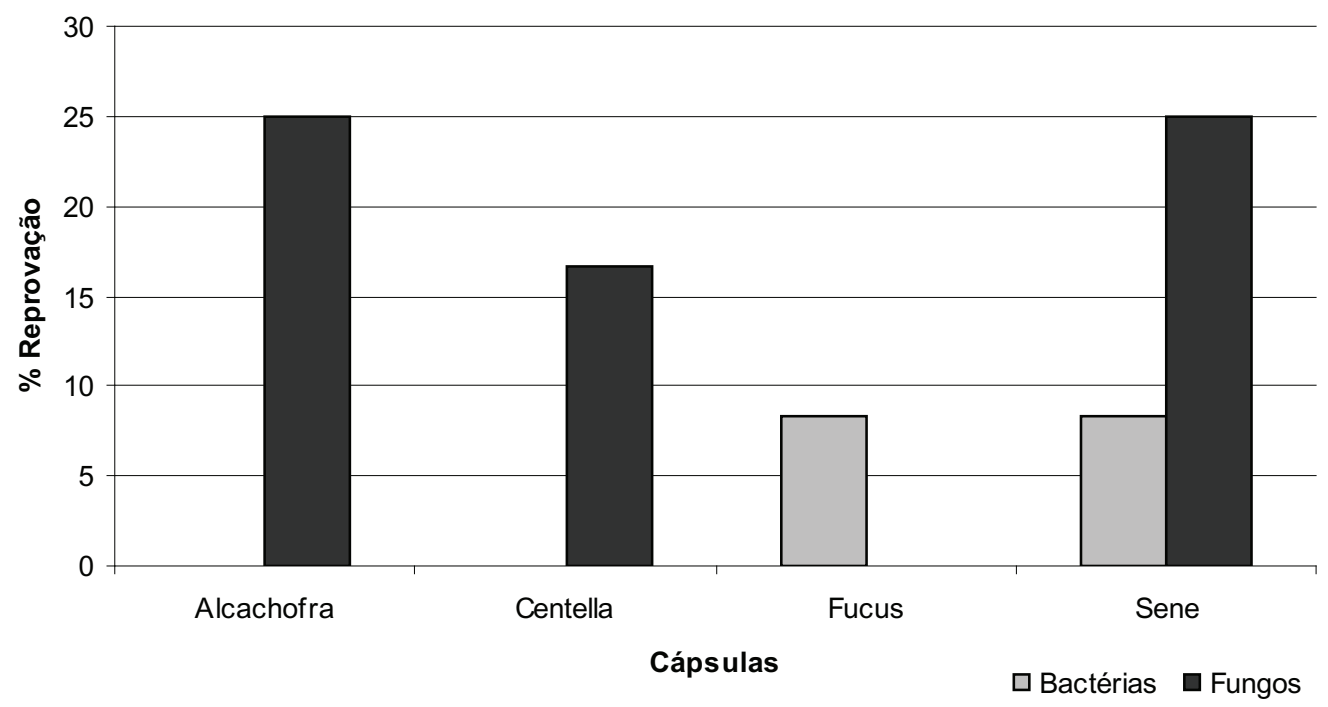

FIGURA 1. Representação do percentual de reprovação das cápsulas em relação à contagem de bactérias e fungos viáveis.

crescimento no ágar verde brilhante e o chá do fornecedor $\mathrm{C}$ no ágar Vogel Jhonson e, ambas as cápsulas dos fornecedores A e B apresentaram crescimento no ágar verde brilhante, enquanto as cápsulas do fornecedor $E$ não apresentaram crescimento nos meios. Para o fucus, o chá do fornecedor $A$ apresentou crescimento no ágar verde brilhante (dois tipos de colônias com distintos aspectos macroscópicos) e no ágar Vogel Jhonson; as cápsulas dos fornecedores $A$ e $B$ não apresentaram crescimento nos meios e, as cápsulas do fornecedor $\mathrm{E}$ apresentaram crescimento no ágar verde brilhante e no ágar Mac Conkey. Para o sene, o chá do fornecedor A não demonstrou crescimento nos meios, enquanto o chá do fornecedor $C$ apresentou crescimento no ágar verde brilhante, no ágar Mac Conkey e no ágar Vogel Jhonson; por outro lado, o chá do fornecedor $D$ apresentou crescimento no ágar verde brilhante (dois tipos de colônias com distintos aspectos macroscópicos) e, as cápsulas dos fornecedores $A$ e $B$ apresentaram crescimento no ágar verde brilhante; as cápsulas do fornecedor $B$ também apresentaram crescimento no ágar Mac Conkey e as cápsulas do fornecedor E não apresentaram crescimento nos meios. Todos os chás e cápsulas que apresentaram crescimento foram subsequentemente testados para as provas confirmatórias e identificação do micro-organismo, sendo que, para aquelas amostras que apresentaram mais de um tipo de colônia, os ensaios de identificação foram realizados para as duas colônias.

Os resultados das provas confirmatórios e de identificação dos micro-organismos na pesquisa de patógenos encontram-se nas tabelas 2 e 3 .

\section{DISCUSSÃO}

As especificações comumente usadas para materiais de origem vegetal encontram-se resumidos na tabela 4. Para os chás se aceita um limite maior, pois antes do uso normalmente adiciona-se água fervente. Nos limites microbiológicos estabelecidos na $5^{a}$ Edição da Farmacopeia Brasileira (Brasil, $2010 \mathrm{~b}$ ), os produtos de origem vegetal foram classificados de acordo com o uso, onde as cápsulas se inserem na categoria de produtos que serão administrados via oral (V.O.) e, os chás pertencem à categoria de drogas vegetais que serão submetidas a processos extrativos a quente. Esta classificação é mais apropriada e rigorosa para os produtos de origem vegetal. Os chás são drogas vegetais que passam por processos de coleta e secagem podendo estar na forma íntegra, rasurada, triturada ou pulverizada, não sendo, portanto, medicamentos fitoterápicos. Contudo as cápsulas se enquadram no conceito de fitoterápicos pois são medicamentos obtidos de matérias-primas exclusivamente vegetais e, devem possuir registro de medicamentos quando fabricados industrialmente, além de laudo de controle de qualidade que incluem avaliação microbiológica (Brasil, 2010a). Na Resolução RDC n 12 de 2001, os chás são classificados como alimentos por não possuírem indicação terapêutica e, nesta resolução se encontram os limites microbiológicos para produtos que serão consumidos após a adição de líquido com emprego de calor (mínimo $75^{\circ} \mathrm{C}$, durante 20 s) (Brasil, 2001). Em relação aos fitoterápicos, a Coordenação de Fitoterápicos, Dinamizados e Notificados (COFID) em 2009, publicou os limites microbiológicos que podem ser aceitos (Brasil, 2009), sendo estes semelhantes aos estabelecidos para produtos não estéreis em geral na $4^{\mathrm{a}}$ Edição 
TABELA 2. Resultados encontrados na pesquisa de patógenos nas provas confirmatórias.

\begin{tabular}{|c|c|c|c|c|c|c|c|c|c|c|}
\hline $\begin{array}{l}\text { Planta } \\
\text { medicinal }\end{array}$ & $\begin{array}{l}\text { Produto/ } \\
\text { Fornecedor }\end{array}$ & TSI & Lisina & Uréia & Citrato & SIM & Catalase & Coagulase & $\begin{array}{l}\text { Mueller } \\
\text { Hinton }\end{array}$ & Oxidase \\
\hline \multirow[t]{6}{*}{ Alcachofra } & Chá/ A & A/VGás - $\mathrm{H}_{2} \mathrm{~S}-$ & - & - & + & I- M- & + & - & - & - \\
\hline & Chá/ C & NA & NA & NA & NA & NA & + & - & NA & NA \\
\hline & Chá/ D & A/VGás $+\mathrm{H}_{2} \mathrm{~S}-$ & + & - & + & $\mathrm{I}-\mathrm{M}+$ & NA & NA & NA & NA \\
\hline & Cáps/ AColônia 1 & A/VGás $+\mathrm{H}_{2} \mathrm{~S}-$ & + & + & + & $\mathrm{I}+\mathrm{M}+$ & NA & NA & - & - \\
\hline & Cáps/ AColônia 2 & A/VGás - $\mathrm{H}_{2} \mathrm{~S}$ - & - & - & + & $\mathrm{I}+\mathrm{M}-$ & NA & NA & NA & NA \\
\hline & Cáps/ B & NA & NA & NA & NA & NA & + & - & NA & NA \\
\hline \multirow[t]{4}{*}{ Centella } & Chá/ A & AGás $+\mathrm{H}_{2} \mathrm{~S}-$ & + & + & + & $\mathrm{I}-\mathrm{M}+$ & NA & NA & NA & NA \\
\hline & Chá/ C & NA & NA & NA & NA & NA & + & - & NA & NA \\
\hline & Cáps/ A & A/VGás $+\mathrm{H}_{2} \mathrm{~S}+$ & + & - & + & I- M- & NA & NA & NA & NA \\
\hline & Cáps/ B & A/VGás $+\mathrm{H}_{2} \mathrm{~S}+$ & + & - & + & I- M- & NA & NA & NA & NA \\
\hline \multirow[t]{3}{*}{ Fucus } & Chá/ AColônia 1 & A/VGás $-\mathrm{H}_{2} \mathrm{~S}+$ & + & - & - & $\mathrm{I}-\mathrm{M}-$ & + & - & NA & NA \\
\hline & Chá/ AColônia 2 & A/VGás $+\mathrm{H}_{2} \mathrm{~S}-$ & + & - & + & I- M- & NA & NA & NA & NA \\
\hline & Cáps/ E & A/VGás $+\mathrm{H}_{2} \mathrm{~S}+$ & + & - & - & I- M- & NA & NA & NA & NA \\
\hline \multirow[t]{5}{*}{ Sene } & Chá/ C & A/VGás $+\mathrm{H}_{2} \mathrm{~S}-$ & - & - & + & $I+M-$ & + & - & NA & NA \\
\hline & Chá/ DColônia 1 & A/VGás $+\mathrm{H}_{2} \mathrm{~S}-$ & - & - & + & $\mathrm{I}-\mathrm{M}+$ & NA & NA & NA & NA \\
\hline & Chá/ DColônia 2 & A/VGás $+\mathrm{H}_{2} \mathrm{~S}-$ & + & - & - & $\mathrm{I}-\mathrm{M}+$ & NA & NA & NA & NA \\
\hline & Cáps/ A & A/VGás $+\mathrm{H}_{2} \mathrm{~S}-$ & + & - & - & I- M- & NA & NA & NA & NA \\
\hline & Cáps/ B & A/VGás $+\mathrm{H}_{2} \mathrm{~S}-$ & + & - & + & I- M- & NA & NA & NA & NA \\
\hline
\end{tabular}

"+": crescimento positivo; "-": nenhum crescimento; TSI: meio que apresenta glicose, sucrose e lactose e, as bactérias fermentadoras destes açúcares convertem o meio de vermelho para amarelo: "A" meio ficou amarelo, "V" meio ficou vermelho; Gás: "+" formou gás; "-" não formou gás; $\mathrm{H}_{2} \mathrm{~S}$ : "+" formou pontos pretos (sulfeto de hidrogênio), "-" não formou; Lisina: descarboxilação "-" meio roxo com base amarela, descarboxilação "+" meio roxo, desaminação "+" meio roxo com superfície vermelha;; Uréia: "-" meio permaneceu laranja, "+" meio mudou para rosa; Citrato: "-" meio permaneceu verde, "+" meio mudou para azul; SIM (Sulfeto Indol Motilidade): "I+" produziu indol (após adição de reagente de Kovac), "I-" não produziu indol, "M-" não apresentou motilidade, "M+" apresentou motilidade; "NA": não se aplica.

TABELA 3. Micro-organismos encontrados nos chás e cápsulas.

\begin{tabular}{lll}
\hline Planta medicinal & Produto/ Fornecedor & Micro-organismo encontrado \\
\hline Alcachofra & Chá/ A & Enterobacter sp. e Staphylococcus coagulase negativo \\
& Chá/ C & Staphylococcus coagulase negativo \\
& Chá/ D & Salmonella sp. \\
& Cápsula/ A & Providencia e Klebsiella sp. \\
& Cápsula/ B & Staphylococcus coagulase negativo \\
Chá/ A & Klebsiella sp. \\
Chá/ C & Staphylococcus coagulase negativo \\
& Cápsula/ A & Salmonella sp. \\
& Cápsula/ B & Salmonella sp. \\
Chál A & Salmonella sp., Enterobacter sp. e Staphylococcus coagulase negativo \\
Cápsula/ E & Salmonella sp. \\
Chá/ C & Proteus sp.e Staphylococcus coagulase negativo \\
& Chá/ D & Enterobacter sp. e Salmonella sp. \\
& Cápsula/ A & Salmonella sp. \\
& Cápsula/ B & Enterobacter sp. \\
& &
\end{tabular}


TABELA 4. Especificações comumente usadas como critério para aprovação ou reprovação de materiais vegetais.

\begin{tabular}{|c|c|c|c|c|}
\hline Especificação & $\begin{array}{l}\text { Produto } \\
\text { vegetal }\end{array}$ & Bactérias & Fungos & Micro-organismos específicos \\
\hline
\end{tabular}

\begin{tabular}{|c|c|c|c|c|}
\hline \multirow[t]{2}{*}{$\begin{array}{l}\text { Farmacopeia } \\
\text { Brasileira } 5^{\mathrm{a}} \text { Ed. } \\
\text { (Brasil, 2010b) }\end{array}$} & $\begin{array}{l}\text { Preparação para uso oral } \\
\text { contendomatéria-prima de origem } \\
\text { natural (como as cápsulas) }\end{array}$ & $\begin{array}{l}\text { No máximo } 2 \\
\times 10^{4} \mathrm{UFC} / \mathrm{g}\end{array}$ & $\begin{array}{l}\text { No máximo } 2 \\
\times 10^{2} \text { UFC/ g }\end{array}$ & $\begin{array}{l}\text { Escherichia coli: ausência/g } \\
\text { Staphylococcus aureus: ausência/g } \\
\text { Salmonella: ausência/g } \\
\text { Outras enterobactérias: no máximo } 2 \times 10^{2} \\
\text { UFC/g }\end{array}$ \\
\hline & $\begin{array}{l}\text { Drogas vegetais que serão } \\
\text { submetidas a processos extrativosa } \\
\text { quente (como os chás) }\end{array}$ & $\begin{array}{l}\text { No máximo } 2 \\
\times 10^{7} \mathrm{UFC} / \mathrm{g}\end{array}$ & $\begin{array}{l}\text { No máximo } 2 \\
x 10^{4} \mathrm{UFC} / \mathrm{g}\end{array}$ & $\begin{array}{l}\text { Escherichia coli: no máximo } 2 \times 10^{2} \mathrm{UFC} / \mathrm{g} \\
\text { Salmonella: ausência/10g } \\
\text { Outras enterobactérias: no máximo } 2 \times 10^{4} \\
\text { UFC/g }\end{array}$ \\
\hline
\end{tabular}

\begin{tabular}{|c|c|c|c|c|}
\hline $\begin{array}{l}\text { Coordenação de } \\
\text { Fitoterápicos, } \\
\text { Dinamizados } \\
\text { e Notificados } \\
\text { (COFID) (Brasil, } \\
2009 \text { ) }\end{array}$ & Fitoterápicos (como as cápsulas) & $\begin{array}{l}\text { No máximo } 5 \\
\times 10^{3} \mathrm{UFC} / \mathrm{g}\end{array}$ & $\begin{array}{l}\text { No máximo } 5 \\
\times 10^{2} \text { UFC/ g }\end{array}$ & Não descrito. \\
\hline
\end{tabular}

\begin{tabular}{|c|c|c|c|c|}
\hline $\begin{array}{l}\text { RDC } n^{\circ} 12 \text { de } \\
2001 \text { (Brasil, } \\
2001)^{*}\end{array}$ & $\begin{array}{l}\text { Produtos que serão consumidos } \\
\text { após a adição de líquido quente } \\
\text { (mínimo } 75^{\circ} \mathrm{C} \text { por } 20 \mathrm{~s} \text { ) (como os } \\
\text { chás) }\end{array}$ & Não descrito. & Não descrito. & $\begin{array}{l}\text { Escherichia coli: no máximo } 10^{3} \mathrm{UFC} / \mathrm{g} \\
\text { Salmonella: ausência }\end{array}$ \\
\hline \multirow[t]{2}{*}{$\begin{array}{l}\text { Farmacopeia } \\
\text { Britânica (British } \\
\text { Pharmacopoeia, } \\
\text { 2007) }\end{array}$} & $\begin{array}{l}\text { Produtos vegetais onde não será } \\
\text { adicionada água quente antes do } \\
\text { uso (como as cápsulas) }\end{array}$ & $\begin{array}{l}\text { No máximo } 5 \\
\times 10^{5} \mathrm{UFC} / \mathrm{g}\end{array}$ & $\begin{array}{l}\text { No máximo } 5 \\
\times 10^{4} \mathrm{UFC} / \mathrm{g}\end{array}$ & $\begin{array}{l}\text { - Escherichia coli: ausência/ g } \\
\text { - Salmonella: ausência/ } 10 \mathrm{~g} \\
\text { - Outras Enterobactérias e bactérias gram } \\
\text { negativas: no máximo } 5 \times 10^{3} \mathrm{UFC} / \mathrm{g}\end{array}$ \\
\hline & $\begin{array}{l}\text { Produtos vegetais onde será } \\
\text { adicionada água quente antes do } \\
\text { uso (como os chás) }\end{array}$ & $\begin{array}{l}\text { No máximo } 5 \\
\times 10^{7} \mathrm{UFC} / \mathrm{g}\end{array}$ & $\begin{array}{l}\text { No máximo x } \\
10^{5} \mathrm{UFC} / \mathrm{g}\end{array}$ & Escherichia coli: no máximo $5 \times 10^{2} \mathrm{UFC} / \mathrm{g}$ \\
\hline \multirow[t]{3}{*}{ OMS (WHO 1998) } & $\begin{array}{l}\text { Material vegetal cru destinado a } \\
\text { processamento futuro }\end{array}$ & & $\begin{array}{l}\text { No máximo } 5 \\
\times 10^{5} \mathrm{UFC} / \mathrm{g}\end{array}$ & Escherichia coli: no máximo $10^{4} \mathrm{UFC} / \mathrm{g}$ \\
\hline & $\begin{array}{l}\text { Material vegetal pré-tratado com } \\
\text { água fervente (como os chás) }\end{array}$ & $\begin{array}{l}\text { No máximo } 5 \\
\times 10^{7} \mathrm{UFC} / \mathrm{g}\end{array}$ & $\begin{array}{l}\text { No máximo } 5 \\
\times 10^{3} \mathrm{UFC} / \mathrm{g}\end{array}$ & $\begin{array}{l}\text { Escherichia coli: no máximo } 5 \times 10^{2} \mathrm{UFC} / \mathrm{g} \\
\text { Salmonella: ausência } \\
\text { Outras enterobactérias: no máximo } 5 \times 10^{2} \\
\text { UFC/g }\end{array}$ \\
\hline & $\begin{array}{l}\text { Material vegetal para uso interno } \\
\text { (como as cápsulas) }\end{array}$ & $\begin{array}{l}\text { No máximo } 5 \\
\times 10^{5} \mathrm{UFC} / \mathrm{g}\end{array}$ & $\begin{array}{l}\text { No máximo } 5 \\
\times 10^{3} \mathrm{UFC} / \mathrm{g}\end{array}$ & $\begin{array}{l}\text { Escherichia coli: no máximo } 5 \times 10^{1} \mathrm{UFC} / \mathrm{g} \\
\text { Salmonella: ausência } \\
\text { Outras enterobactérias: no máximo } 5 \times 10^{3} \\
\text { UFC/g }\end{array}$ \\
\hline \multirow[t]{3}{*}{$\begin{array}{l}\text { Farmacopeia } \\
\text { Americana } \\
\text { (USP, 2007) }\end{array}$} & Plantas secas ou pulverizadas & $\begin{array}{l}\text { No máximo } 5 \\
\times 10^{5} \mathrm{UFC} / \mathrm{g}\end{array}$ & $\begin{array}{l}\text { No máximo } 5 \\
\times 10^{3} \mathrm{UFC} / \mathrm{g}\end{array}$ & $\begin{array}{l}\text { Escherichia coli: ausência/ } 10 \mathrm{~g} \\
\text { Salmonella: ausência/ } 10 \mathrm{~g} \\
\text { Bactérias gram negativas bile tolerantes: } \\
\text { no máximo } 5 \times 10^{3} \mathrm{UFC} / \mathrm{g}\end{array}$ \\
\hline & $\begin{array}{l}\text { Extrato de plantas pulverizadas } \\
\text { (como as cápsulas) }\end{array}$ & $\begin{array}{l}\text { No máximo } 5 \\
\times 10^{4} \mathrm{UFC} / \mathrm{g}\end{array}$ & $\begin{array}{l}\text { No máximo } 5 \\
\times 10^{3} \mathrm{UFC} / \mathrm{g}\end{array}$ & $\begin{array}{l}\text { Escherichia coli: ausência/ } 10 \mathrm{~g} \\
\text { Salmonella: ausência/ } 10 \mathrm{~g}\end{array}$ \\
\hline & $\begin{array}{l}\text { Plantas tratadas com água ferventes } \\
\text { antes do uso (como os chás) }\end{array}$ & $\begin{array}{l}\text { No máximo } 5 \\
\times 10^{5} \mathrm{UFC} / \mathrm{g}\end{array}$ & $\begin{array}{l}\text { No máximo } 5 \\
\times 10^{3} \mathrm{UFC} / \mathrm{g}\end{array}$ & Escherichia coli: ausência/ $10 \mathrm{~g}$ \\
\hline
\end{tabular}

* Na RDC 12 de 2001 (Brasil, 2001), Escherichia coli é denominada de coliformes termotolerantes. 
da Farmacopeia Brasileira (1988).

Todas as especificações citadas na tabela 4 encontram-se em vigor. Dependendo da referência utilizada, os resultados de aprovação das amostras podem variar, por isso neste trabalho optou-se por utilizarmos as especificações determinadas na Farmacopeia Brasileira $5^{\text {a }}$ Ed., pois os insumos farmacêuticos, os medicamentos e outros produtos sujeitos à vigilância sanitária devem atender às normas e especificações estabelecidas nesta (Brasil, 2010b). Neste contexto, percebe-se a necessidade de unificação/padronização dos limites microbiológicos de aceitação, para uma melhor interpretação das análises pelo operador e principalmente para a segurança do consumidor.

Em relação aos dados obtidos, segundo a tabela 1, para as cápsulas os níveis encontrados de contaminação por bactérias viáveis variaram de 0 a $1,44 \times 10^{5} \mathrm{UFC} / \mathrm{g}$ e, para fungos de 0 a $1,11 \mathrm{x}$ $10^{4} \mathrm{UFC} / \mathrm{g}$. Para os chás os níveis de contaminação para bactérias variaram de 0 a 1,64 x $10^{5} \mathrm{UFC} / \mathrm{g}$ e, para fungos de 0 a $6,74 \times 10^{3} \mathrm{UFC} / \mathrm{g}$.

Dessa forma, todos os chás analisados foram aprovados quanto ao número de bactérias e fungos viáveis. Entretanto, observou-se que 16,66\% das cápsulas analisadas foram reprovadas por apresentarem quantidades superiores de bactérias e $66,66 \%$ foram reprovadas por apresentarem quantidades superiores de fungos. A qualidade das cápsulas foi decrescente na ordem: fucus > centella $>$ alcachofra $>$ sene, conforme a figura 1. Este alto percentual de reprovação está relacionado aos limites microbiológicos mais rigorosos estabelecidos (principalmente em relação à contaminação fúngica) pela F. Bras. 5a Ed. (Brasil, 2010b), sendo estes limites coerentes com os outros produtos utilizados via oral de origem sintética.

As três amostras de cápsulas de alcachofra analisadas apresentaram contagem de fungos acima do permitido (fornecedores A, B e E). Nas cápsulas de centella, duas das três amostras analisadas apresentaram contagem de fungos superior aos limites (fornecedores B e E), e uma das três amostras de cápsulas de fucus, apresentou contagem de bactérias acima dos limites (fornecedor B). Nas três amostras de cápsulas de sene todas apresentaram a contagem de fungos acima das especificações (fornecedor A, B e E) e uma destas apresentou também contagem de bactérias acima dos limites (fornecedor B).

Em relação aos fornecedores/ fabricantes das cápsulas, as amostras adquiridas dos fornecedores "B" e "E" apresentaram contaminação bacteriana e principalmente fúngica acima dos limites, demonstrando falhas no controle de qualidade destes fabricantes, além da provável aquisição de matérias-primas vegetais de má qualidade para a produção das cápsulas.

Para os chás, a alcachofra e o sene do fornecedor D, apesar de estarem dentro das especificações para chás, apresentaram as maiores contaminações. A qualificação de fornecedores e o controle da contaminação microbiana é um aspecto importante das Boas Práticas de Fabricação e deve ser parte integrante do programa de garantia de qualidade (Bugno et al., 2003).

No caso dos chás poderíamos ter obtido diferentes resultados se as análises fossem realizadas após a infusão que consiste em verter água fervente sobre a planta medicinal, tapar o recipiente para que não se percam as essências voláteis e aguardar 10 minutos. Provavelmente, após este procedimento a contaminação seria menor, pois a água fervente auxilia na eliminação dos microorganismos. No entanto, ressalta-se a importância dos chás estarem livres de contaminação prévia, pois a contaminação pode permanecer dependendo das condições empregadas no processo de infusão. Para assegurar que o infuso consumido esteja livre de contaminação microbiana, devem ser empregados temperaturas e tempos de contato suficientes, o que na prática nem sempre acontece (Gomes et al., 2008).

$\mathrm{Na}$ pesquisa de patógenos os ensaios foram qualitativos, indicando apenas a presença, sem a quantificação exata do número de UFC. Havendo crescimento das amostras enriquecidas em caldo nos meios seletivos realizou-se uma série de provas para a confirmação do micro-organismo (tabela 2). Na tabela 3 encontram-se a relação dos micro-organismos encontrados, sendo que das 21 amostras analisadas, 16 apresentaram algum tipo de micro-organismo, representando $76 \%$ das amostras. Os micro-organismos estiveram presentes em $88 \%$ dos chás analisados e em $58 \%$ das cápsulas. Salmonella sp. esteve presente em $33 \%$ das amostras, Staphylococcus sp. (coagulase negativo) em $28 \%$, e Enterobacter sp. em 19\% das amostras. As amostras que apresentaram Salmonella sp. (chá de alcachofra/fornecedor D, cápsulas de centella/ fornecedor $A$ e $B$, chá de fucus/ fornecedor A, cápsulas de fucus/ fornecedor $E$, chá de sene/ fornecedor $\mathrm{D}$, cápsulas de sene / fornecedor A) podem ser consideradas reprovadas nestas análises, pois segundo as especificações (WHO, 1998; British Pharmacopoea, 2007; Brasil, 2010 b) produtos de origem vegetal utilizados via oral que apresentem Salmonella sp. são considerados impróprios para o consumo. A presença de cepas patogênicas representa risco de aquisição de quadro clínico infeccioso ou de transferência de toxina indesejáveis, sendo imprescindível sua determinação.

Segundo Araújo \& Ohara (2000), Klebsiella

Rev. Bras. PI. Med., Campinas, v.15, n.4, p.494-502, 2013. 
sp., Enterobacter sp. e Citrobacter sp. são comuns em matérias-primas vegetais, uma vez que estão relacionados ao meio ambiente das plantas, não sendo necessariamente de origem fecal.

Os resultados obtidos evidenciaram que mais de $60 \%$ das cápsulas, consideradas produtos fitoterápicos, apresentaram contagem microbiana acima dos limites de aceitação (Brasil, 2010b). Os chás foram considerados aprovados, pois apesar de apresentarem uma carga microbiana elevada, esta se encontrava dentro dos limites especificados. $\mathrm{Na}$ pesquisa de patógenos, $76 \%$ das amostras apresentaram um ou mais de um tipo de microorganismo, sendo que Salmonella sp. esteve presente em $33 \%$ das amostras. Estes dados evidenciam a qualidade microbiológica insatisfatória dos produtos encontrados no mercado, demonstrando a falta de preocupação dos fabricantes/ fornecedores em obter matéria-prima vegetal de boa procedência e qualidade comprovada, e a falta de controle de qualidade dos produtos acabados.

Estes resultados demonstram a necessidade de controle de qualidade destes produtos de origem vegetal amplamente utilizados no combate à obesidade, através do controle e fiscalização rigorosa, com adoção de medidas regulamentadoras e educativas. Além disso, é necessário, definir ações adequadas de boas práticas de fabricação e controle para garantir a qualidade e segurança deste tipo de produto desde a coleta, armazenamento e manipulação até o produto final.

\section{REFERÊNCIA}

ABESO- Associação Brasileira para o Estudo da Obesidade. Dados Epidemiológicos sobre Obesidade. Disponível em: <http://www.abeso.org. br>. Acessado em: 09 junho de 2011.

ARAÚJO, A.L.A; OHARA, M.T. Qualidade microbiológica de drogas vegetais comercializadas em feira de São Paulo e de infusos derivados. Revista Brasileira de Ciências Farmacêuticas, v.36, p.129-137, 2000.

BIANCO, M.I; LÚQUEZ, C.; JONG, L.I.T; FERNANDES, R.A. Presence of Clostridium botulinum spores in Matricaria chamomilla (chamomile) and its relationship with infant botulism. International Journal of Food Microbiology, v.121, n.3, p.357-60, 2008.

BRASIL. Ministério da Saúde. Agência Nacional de Vigilância Sanitária. Resolução RDC $n^{\circ} 12$, de 2 de janeiro de 2001. Regulamento técnico sobre os padrões microbiológicos para alimentos. DOU. Poder Executivo, Brasília, DF, 10 janeiro 2001.

BRASIL. Ministério da Saúde. Agência Nacional de Vigilância Sanitária. Consolidado de Normas da COFID. Brasília, outubro 2009.

BRASIL. Ministério da Saúde. Agência Nacional de Vigilância Sanitária. Resolução RDC n 14, de 31 de março de 2010. Dispões sobre o registro de medicamentos fitoterápicos. DOU. Poder Executivo, Brasília, DF, 5 abril 2010a.

BRASIL. Agência Nacional de Vigilância Sanitária. Farmacopeia Brasileira $5^{a}$ Ed., volume 1. Brasília: ANVISA, 2010b. 546p.

BRASIL. Ministério da Saúde. Agência Nacional de Vigilância Sanitária. Resolução RDC $n^{\circ} 52$, de 6 de outubro de 2011. Dispõe sobre a proibição do uso das substâncias anfepramona, femproporex e mazindol, seus sais e isômeros, bem como intermediários e medidas de controle da prescrição e dispensação de medicamentos que contenham a substância sibutramina, seus sais e isômeros, bem como intermediários e dá outras providências. DOU. Poder Executivo, Brasília, DF, 10 outubro 2011.

BRITISH PHARMACOPOEIA, CD-ROM, version 11.0, 2007.

BUGNO, A.; BUZZO, A.A.; PEREIRA, T.C. Avaliação da Qualidade Microbiológica de Produtos Saneantes Destinados à Limpeza. Revista Brasileira de Ciências Farmacêuticas, v.39, n.3, p.335-340, 2003.

CARVALHO, A.C.B.; BALBINO, E.E.; MACIEL, A.; PERFEITO, J.P.S. Situação do registro de medicamentos fitoterápicos no Brasil. Revista Brasileira de Farmacognosia, v.18, n.2, p. 314-319, 2008.

D'IPPOLITO, J.A.C.; ROCHA, L.M.; SILVA, R.F. Fitoterapia Magistral: Um guia prático para a manipulação de fitoterápicos. 1.ed. São Paulo: Anfarmag, 2005. 194p.

FARMACOPEIA BRASILEIRA. 4.ed. São Paulo: Atheneu. 1988.

GOMES, E.C.; NEGRELLE, R.R.B.; ELPO, E.R.S. Determinação da qualidade microbiológica e físicoquímica de chás de Cymboogon citratus (D.C) Stapf (capim-limão). Acta Scientiarum: Health Science, v.30, n.1, p.47-54, 2008.

LIMYATI, D.A.; JUNIAR, B.L.L. Jamu Gendong, a kind of traditional medicine in Indonesia: the microbial contamination of its raw materials and endproduct. Journal of Ethnopharmacology, v.63, p.201-208, 1998.

LUIZA, V.L.; CASTRO, C.G.S.O.; NUNES, J.M. Aquisição de medicamentos no setor público: o binômio qualidadecusto. Caderno de Saúde Pública, v.15, n.4, p. 769776. 1999.

MARTINS, H.M.; MARTINS, M.L.; DIAS, M.I.; BERNARDO, F. Evaluation of microbiological quality of medicinal plants used in natural infusions. International Journal of Food Microbiology, v.68, p.149-153, 2001.

MÜLLER, P.; BASEDOW, T. Aflatoxin contamination of pods of Indian Cassia senna L. (Caesalpinaceae) before harvest, during drying and in storage: Reasons and possible methods of reduction. Journal of Stored Products Research, v.43, p.323-329, 2007.

PINTO, T.J.A.; KANEKO, T.M.; OHARA, M.T. Controle biológico de qualidade de produtos farmacêuticos, correlatos e cosméticos. 2.ed.São Paulo: Atheneu, 2003. 325p.

ROCHA, L.O.; SOARES, M.M.S.R.; CORREAA, C.L. Análise da contaminação fúngica em amostras de Cassia acutifolia Delile (sene) e Peumus boldus (Molina) Lyons (boldo-do-Chile) comercializadas na cidade de Campinas, Brasil. Revista Brasileira de Ciências Farmacêuticas, v.40, n.4, p.521-527, 2004. 
TESKE, M.; TRENTINI, A.M.M. Herbarium: Compêndio de Fitoterapia. 3.ed. Curitiba: Herbarium, 1995. 318p. UNITED STATES PHARMACOPOEIA, USP 30, NF 25. Chapter 2023 Microbiological attributes of nonsterile nutritional and dietary supplements, 2007.

ZARONI, M.; PONTAROLO, R.; ABRAHÃO, W.S.M.; FÁVERO, M.L.D.; CORREA JÚNIOR, C.; STREMEL, D.P. Qualidade microbiológica das plantas medicinais produzidas no Estado do Paraná. Revista Brasileira de Farmacognosia, v.14, n.1, p.29-39, 2004.

WHO - WORLD HEALTH ORGANIZATION. Quality control methods for medicinal plant materials. Geneva: WHO, 1998.

WHO - WORLD HEALTH ORGANIZATION. Quality control methods for medicinal plant materials. Geneva: WHO, 2003. 